EESTI NSV TEADUSTE AKADEEMIA TOIMETISED. 19. KÖIDE

KEEMIA * GEOLOOGIA. 1970, NR. 3

ИЗВЕСТИЯ АКАДЕМИИ НАУК ЭСТОНСКОИ ССР. ТОМ 19

ХИМИЯ * ГЕОЛОГИЯ. 1970 , № 3

\title{
Я.-М. ПУННИНГ
}

\section{О ПОГРЕШНОСТЯХ РАДИОУГЛЕРОДНОГО МЕТОДА И О КОНТРОЛЕ ДОСТОВЕРНОСТИ ПОЛУЧЕННЫХ ДАТ}

В связи с широким применением данных радиоуглеродного метода летоисчисления в геологии, археологии и других научных дисциплинах возрастают и требования, предъявляемые этому методу. Все острее поднимается вопрос о достоверности полученных радиоуглеродных дат.

Причины всех возникающих погрешностей можно разделить на сле. дующие три группы (Olson, Broecker, 1958; Кинд, Алексеев, 1963): 1) основные предпосылки радиоуглеродного метода неприменимы к данному образцу; 2) неправильное измерение концентрации $\mathrm{C}^{14}$ в образце и 3) неправильная интерпретация данных.

Многие причины, вызывающие несовпадение содержания $\mathrm{C}^{14}$ в исследуємом объекте (во время его участия в круговороте углерода) и в аналогичном современном материале, подробно описаны и доказано, что при введении соответствующих поправок, возникающие погрешности обычно относительно невелики. Меньшее внимание уделялось загрязнению, обусловленному питанием растений более древним углеродом (Deevey и др., 1954; Арсланов, 1963). Как показывают исследования некоторых авторов (Miller, 1960; Исследование метаболизма растений изотопными методами, 1963 ; и др.) $\mathrm{CO}_{2}$ и $\mathrm{HCO}_{3}^{-}$ассимилируются в значительных количествах корнями растений и накапливаются в стеблях и листьях в виде сахара, белка и органических кислот. Это значит, что растения, обитающие на древних карбонатных породах или в водоемах с жесткой водой, во время своей жизнедеятельности загрязняются древним углеродом. Наверно это является причиной выявленного значительного «удревнения» гипнового торфа из слоя известкового алеврита разреза Лообу в Северной Эстонии (ТА-137, 138). Полученные значения возрастов (13900-14700 лет) превышают на 4-5 тыс. лет предполагаемый возраст этих образцов (IX -X фаза развития лесов). Для такого «удревнения» требуется примесь «мертвого» углерода в количестве почти $50 \%$.

Погрешности в радиоуглеродных датах могут быть вызваны также изотопным фракционированием и вариациями концентрации $\mathrm{C}^{14}$ в атмосфере. Ошибка, обусловленная изменением концентрации $\mathrm{C}^{14}$ на $\pm 1 \%$ в датируемом объекте во время его присутствия в обменном резервуаре, составляет \pm 80 лет. Особенно важно учитывать этот фактор при датировании голоценовых образцов, так как относительная ошибка $\Delta t ; t$ уменьшается при увеличении возраста $t$. Когда на основе определения кокцентрации $\mathrm{C}^{14}$ в дендрохронологически датированных годичных кольцах древесины будут составлены таблицы поправок, тогда можно будет пересчитать до сих пор полученные датировки. 
Значительные погрешности могут возникать и из-за изменения концентрации $\mathrm{C}^{14}$ (не учитывая радиоуглеродный распад) в образце после его выхода из обменного резервуара. Причиной является последующеє загрязнение образцов посторонним углеродом в виде корневищ, карбонатных и гумусовых примесей. Қорневища удаляются главным образом механическим путем, а для выделения карбонатных и гумусовых загрязнений из органических образцов нами применяется кислотная и пирофосфатно-щелочная обработка (Пуннинг и др., 1966). Самый надежный контроль над удалением примесей состоит в датировании разнородных материалов из одного и того же стратиграфического горизонта и в опредслении возраста разных фракций образца. Нами был определен возраст параллельно отсбранных материалов: кость-древесина, сапропель-торф-древесина, растительные остатки-древесина, а также разных фракций этих материалов (по гумусовым веществам, лигнину и целлюлозе).

Группа погрешностей, связанных с неправильным измерением концегтрации $\mathrm{C}^{14}$ в образце, имеет в принципе три источника: 1) неправильный выбор эталонов; 2) загрязнение или изотопное фракционирование в ходе синтеза измеряемого препарата и 3) погрешности, вызванные техникой счета.

Использованный в лаборатории геобиохимии Института зоолстии и ботаники АН ЭССР современный стандарт - древесина 1850 г. - сравнивался со стандартом ГЕОХИ. Фоновый препарат, синтезированный из антрацита и шунгита, в пределах статистической ошибки имел сходную скорость счета с имеющимся в продаже препаратом - бензолом «хч» (для криоскопин). При этом фоновые препараты были синтезированы из ацетилена через карбид кальция и лития (Пуннинг и др., 1966б). Для тримеризации ацетилена использовали циглеровский и алюмосиликатный катализатор, активированный с пятиокисью ванадия (Арсланов, Громова, 1967).

Выравнивание сцинтилляционной эффективности препаратов из датируемых образцов со стандартами осуществлялось путем частичного удаления растворенного кислорода из сцинтиллятора продуванием аргона до получения равной скорости счета, которая проверялась по внешнему $\gamma$-источнику. Измерение образцов проводилось последовательно с измерением эталонов и не менее чем два раза. Для контроля регистрации счета применялись два способа: один из них состоял в графическом изображении времени, за которое набирается установленное число импульсов, второй - в получении сразу цифровых печатных данных.

Что касается ошибок, возникающих из-за неправильной интерпретации полученных данных, то тут можно отметить следующие причины: 1) неучитывание статистического характера радиоуглеродного метода, 2) переоценивание радиоуглеродных дат и неучитывание данных геологического анализа, 3) неправильная геологическая интерпретация датируемого комплекса и др.

Одним из ярких примеров расхождения радиоуглеродных данных являются датировки органогенных отложений разрезов в долинах рр. Мяркис и Ула (Юго-Восточная Литва). Ранние геологические и палинологические исследования (Кондратене, 1963а, б; Мицас 1963) указывали на сходные условия образования и залегания этих органогенных отложений. Только первые радиоуглеродные датировки, проведенные в радиоуглеродной лаборатории ГЕОХИ (Виноградов и др., 1966), были поводом стратиграфической дифференциации этих отложений (Последний Европейский ледниковый покров, 1965). Позже выделение улаского 
мєжстадиала подтвердили даты, полученные в лаборатории Института геологии Литовской ССР (Шулия и др., 1967).

Так как появились сомнения в выделении улаского межстадиала, было предпринято датирование образцов из разреза Зярвинос. Полученные датировки (ТА-124, 125) оказались примерно на 4 -6 тыс. лет моложе датировок Мо-302 и Vs-4 (таблица). Такое расхождение требовало применения тщательного контроля, который осуществлялся следующими способами: 1) межлабораторное одновременное датирование хорошо сохранившегося крупного ствола дерева Pinus silvestris L. (часть ствола была датирована в Швеции в лаборатории Уппсальского ун-та); 2) датирование разнородных материалов из одного и того же стратиграфического горизонта; 3) определение возраста разных фракций образца (лигнин и целлюлоза); 4) повторное геологическое изучение разрезов.

Радиоуглеродные датировки органогенных материалов из обнажений в долинах рр. Мяркис и Ула (по данным разных лабораторий)

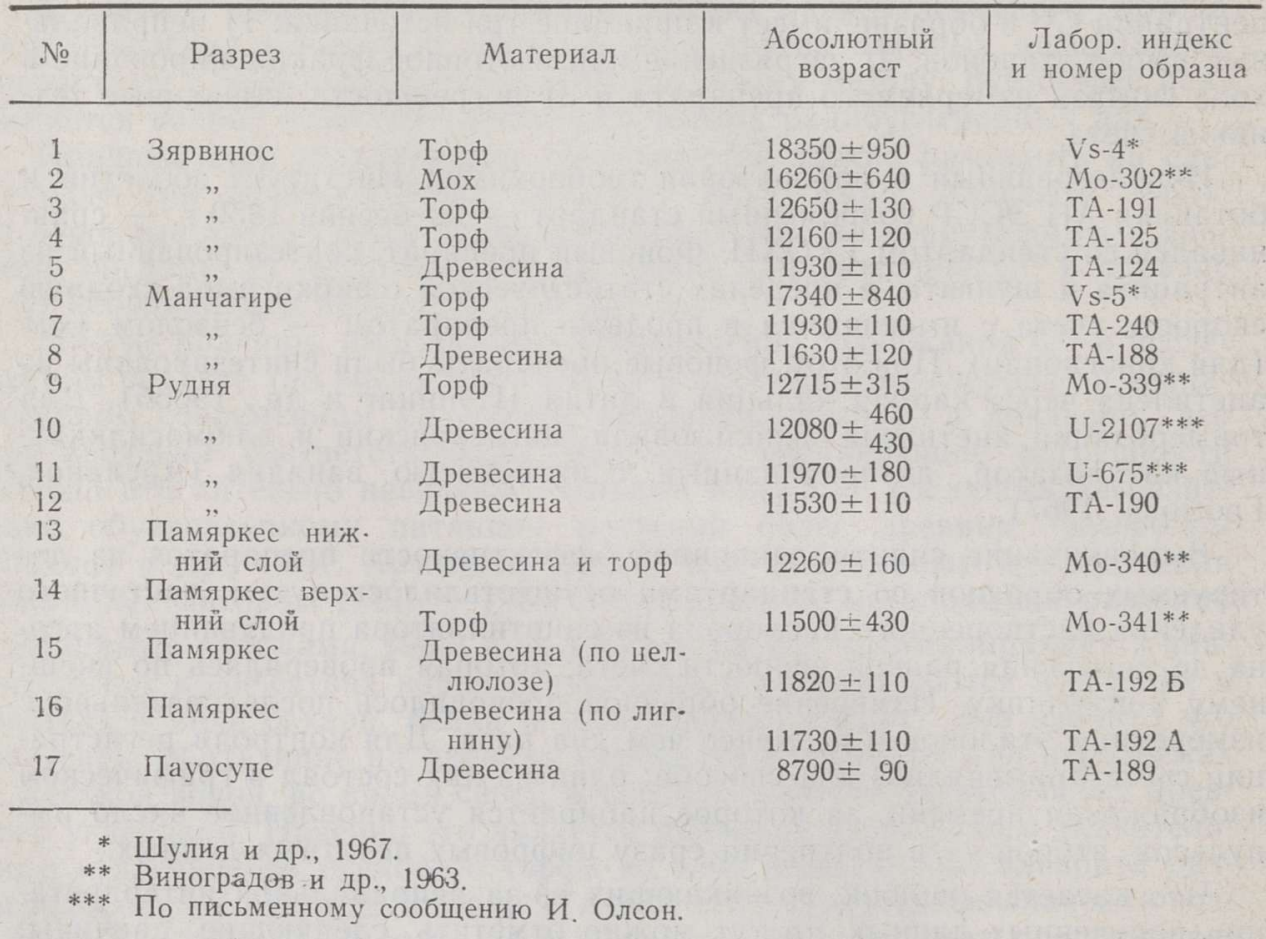

Совпадение полученных возрастов по разнородным материалам, разным фракциям материала и разным методам определения концентрации $\mathrm{C}^{14}$ (в УПпсальской лаборатории пропорциональный, в лаборатории геобиохимии Ин-та зоологии и ботаники АН ЭССР сцінтилляцнонный счетчики) исключает вероятность «омоложения» образцов, могущее возникнуть из-за загрязнения их молодым углеродом, а также исключает по: грешности в процессе приготовления счетного препарата и в процессе счета.

Датированные органогенные отложения перекрыты аллювиалыными и эоловыми песками. Следует отметить, что наличие улаского межстадиала между бранденбургско-франкфуртской и померанской стадиями отрицает также И. Салов (1967), который опирается на изучение термокарстовых и рытвинных озер в Белоруссии. Для окончательного решения 
геологической стороны данного вопроса, однако, необходимо провести тщательные исследования залеганий датируемых органогенных отложений.

Что касается разреза Зярвинос, раньше считавшегося стратотипом для выделения улаского межстадиала, то его геологический возраст уже переоценен (Пиррус и др., 1967; Салов, 1967; Раукас и др., 1968; Вайтекунас, 1969; Вайтекунас, Пуннинг, 1970) и перед радиоуглеродными лабораториями стоит задача выяснить факторы, ответственные за такие большие расхождения в датировках.

Значительные расхождения выявились при датировании разных образцов из одного и того же слоя межморенной толщи разреза ІІээду на северо-западе возвышенности Отепя. По растительным остаткам (ТА-63) получен возраст равный $20670 \pm 1000$ лет, а по крупным обломкам древесины. (ТА-136) - $39180 \pm 1960$ лет. Так как расхождения в датах указывают на явную «омоложенность» первой датировки, то в 1968 году нами вместе с Ә. Лийвранд из буровой скважины были отобраны новые образцы.

Геологическое происхождение межморенной толщи в разрезе Пээду однозначно еще не определено. Чтобы получить достоверные данные, при датировании использовался такой же подход, как и при изучении разрезов в долинах рр. Мяркис и Ула. Был определен возраст древесного торфа (с древесными остатками) и выделенных из основного материала гумусовых веществ. Датирование дало следующие результаты: ТА-254 (основной материал после выделения гумусовых веществ) - $39700 \pm$ \pm 850 лет и ТА-254 А (гумусовые вещества) - $31200 \pm 800$ лет. Если предполагать, что из образца выделена только половина гумусовых веществ, вызывающих «омоложение» на 8500 лет, и что причиной загрязнения был «современный» углерод, то можно вычислить действительный возраст толщи, не превышающий 43000 лет. Поэтому можно считать возрасты $39180 \pm 1960$ и $39700 \pm 850$ лет довольно близкими к истинному. Следует еще отметить, что органогенные отложения в разрезе Пээду покрыты плотной мореной мощностью 6 и и песками мощностью 1,4 , что значительно уменьшает возможность загрязнения. Причиной «омоложения» образца ТА-63 было, наверно, несоблюдение правил отбора образцов.

Когда в исследуемом разрезе нет разнородного материала, для получения более достоверных данных можно датировать кроме разнородных фракций образца несколько послойно отобранных образцов. Последний вариант был выбран при определении возраста погребенного торфяника в Горелово. Первые датировки из этого района были получены в ГЕОХИ - $12150 \pm 390$ лет (Мо-201) (Виноградов и др., 1963) и 9600士 \pm 300 лет (Мо-316) (Виноградов и др., 1966). Нами были датированы четыре образца, отобранные Л. Серебрянным через каждые 2 см. (ТА-184-187). Так как полученные возрасты (от 9470 до 10070 лет) повышаются с глубиной, трудно представить, что загрязнение всего органического комплекса происходило в одинаковой степени. Это позволяет считать полученные нами возрасты достоверными. К этому можно добавигь, что выполненные нами (Серебрянный, Пуннинг, 1969) исследования в долине р. Черной Лиговки вопреки прежним мнениям показали приуроченность органогенных отложений к долине реки и сравнительно ограниченное простирание их вдоль долины, чем еще раз доказана правильность радиоуглеродных дат.

Приведенные нами примеры показывают, что погрешности в радиоуглеродных датах могут быть вызваны многими причинами. Это конечно не дает основание некоторым авторам (Milojčic, 1961; Клейн, 1966) отри- 
цать сам радиоуглеродный метод, но призывает к более тщательному отношению к применяемой методике и отбору образцов.

Для получения достоверных данных необходимо датировать разнородный материал, разные фракции образца, а главным методом контроля должны быть перекрестные анализы между различными лабораториями и интерпретация полученных датировок только в комплексе со всеми геологическими и палеонтологическими данными.

\section{Л И Т Е Р А Т У Р А}

Арсланов Х. А. 1963. Задачи применения радиоуглеродного метода к изучению верхнечетвертичных отложений. В сб.: Абсолютная геохронология четвертичного периода. М.

А рсланов Х. А., Гром о а Л. И. 1967. Авторское свидетельство 1136238/23-4 ог 26 сент. 1967 г.

$\mathrm{B}$ a й т е к у н а с П. П. 1969. О стратиграфическом подразделении неоплейстоцена гляциальной области (на примере Прибалтики). В сб.: Материковое оледенение и ледниковый морфогенез. Вильнюс.

В а й т ек ун а с П. П., Пунн и нг Я.-М. К. 1970. Некоторые итоги исследований палеогеографии и абсолютной хронологии последней ледниковой эпохи в Прибалтике. Baltica, 4. Vilnius. (в печати).

В ин оградов А. П., Д е в и рц А. Л., Добкин а Э. И., М арков а Н. Г. 1963. Данные радиоуглеродной лаборатории Института геохимии и аналитической химин им. В. И. Вернадского. В сб́.: Абсолютная геохронология четвертичного периода. М.

В иноградов А. П., Д ев и ц А. Л., Добкина Э. И., М арков а Н. Г. 1966. Данные радиоуглеродной лаборатории Института геохимии и аналитической химин им. В. И. Вернадского. Верхний плейстоцен, стратиграфия и геохронология. М.

Исследование метаболизма растений изотопными методами. 1963. Сб. М.

К и нд Н. В., А л е к се е в В. А. 1963. Применение различных углеродсодержащих ископаемых материалов для определения абсолютного возраста по радиоуглероду. В сб.: Абсолютная геохронология четвертичного периода. $M$.

К ле йн Л. С. 1966. Археология спорит с физнкой. Природа, № 2, 3.

К ондр а тен е О. П. 1963. Межстадиальные отложения последнего оледенения в долине р. Ула. Тр. АН ЛитССР, Сер. Б., 34, № 3.

Конд ратен е О. П. 1963. Новые разрезы погребенных древнеозерных отложений в долине р. Мяркис. В сб.: Вопросы геологии Литвы. Вильнюс.

Миц а с Л. С. 1963. Террасы долины р. Мяркис. Тр. АН ЛитССР, Сер. Б., 32, № 1.

Пир рус Р., Пуннинг Я.-М., Р а ука с А., С еребрянны й Л. 1967. Абсолютный возраст и стратиграфическое положение уласких межстадиальных отложений Юго-Восточной Литвы. Изв. АН ЭССР, Хим. Геол., 16, № 2.

П.унни и н Я Я.-М., Л и й в а А., И л в в е с Э. 1966. Усовершенствованная методика определения абсолютного возраста по природному радиоуглероду. Изв. АН ЭССР. Сер. физ.-матем. и техн. н., 15, № 2.

Последний Европейский ледниковый покров. 1965. Сб. М.

Р аука с А. В., С ер ебрянный Л. Р., Пунни и г Я.-М. К. 1968. Об́ абсолютном возрасте краевых зон и эволюции оледенения на северо-западе Русской равнины в позднем плейстоцене. Тезисы докл. всесоюзн. межведомственного совещания по изучению краевых образований материкового оледенения. Смоленск.

С ереб рянны й Л. Р., Пунн ин г Я.-М. К. 1969. Результаты радиометрического и палинологического изучения погребенного торфяника в районе ГореловоКойерово под Ленинградом. В сб.: Голоцен. М.

С алов И. Н. 1967. О палеогеографическом значении термокарстовых и рытвинных озер. Материалы II симпозиума по истории озер Северо-Запада СССР. Минск.

Шулия К. С., ЈІ уяна с В. Ю., Киб илда И. К., Генутене И. К. 1967. Датирование по радиоуглероду террас р. Ула Литовской ССР. ДАН СССР, 175, № 1.

Deevey E. S., Gross M. S., Hutchinson G. E., Hen r y L. 1954. The natural C'14 contents of materials from hard-water lakes. Proc. Nat. Acad. Sci., 40, No. 5.

Ols on E. A., B r oecker W. G. 1958. Sample contamination and reliability of radiocarbon dates. Trans. N. Y. Acad. Sci., ser. 2, 20, No. 7.

Miller G. W. 1960. Carbon dioxide-bicarbonate absorption, accumulation effects on various plant metabolic reactions and possibie relations to lime induced clorosis. Soil Sci., 89, No. 5.

Mil o j č i c V. 1961. Zur Anwendbarkeit der $\mathrm{C}^{14}$ Datierung in der Vorgeschichtsforschung. Germania, 39, Nr. $3 / 4$. 


\section{VÕIMALIKEST VIGADEST VANUSE MÄÄRAMISEL LOODUSLIKU RADIOSÜSINIKU $\left(C^{14}\right)$ ABIL JA SAADUD TULEMUSTE KONTROLLIMISEST}

$\mathrm{C}^{14}$ abil vanuse määramisel esinevate vigade põhjused võib jaotada kolme rühma: 1) meetodi pōhieeldused ei kehti antud proovi puhul, 2) ebaõige $C^{14}$ kontsentratsiooni määramine ja 3) tulemuste ebaõige interpretatsioon. Uheks sagedamini esinevaks ekslike tulemuste põhjuseks on lisandite juurdekandumine proovi. Karbonaatsete ja humiinsete lisandite eraldamiseks töödeldakse organogeenset materjali hapetega ja leeliselise pürofosfaadi lahusega. Et tulemuste õigsuses veenduda, tuleb dateerida erinevaid süsinikku sisaldavaidi materjale samast stratigraafilisest horisondist või määrata proovi eri fraktsioonide (huumusained, tselluloos, ligniin) vanus.

Vigade vältimiseks $\mathrm{C}^{14}$ kontsentratsiooni määramisel peab tähelepanu pöörama etaloi-. nide valikule, loenduspreparaadi sünteesi meetodite ja loendusrežiimi kontrollile.

Esitatakse mõned näited $\mathrm{C}^{14}$ dateeringute kontrollimise vajadusest ja selle teostamisest..

\section{J.-M. PUNNING}

\section{ON POSSIBLE ERRORS IN THE DETERMINATION OF SAMPLE AGE BY MEANS OF' RADIOACTIVE CARBON $\left(\mathrm{C}^{14}\right)$ AND ON THE CHECKING OF RESULTS}

The causes of errors possible in determining sample age may be classified into three groups: 1) non-validity of the basic preconditions underlying the method in the case of a given sample, 2) incorrect determination of the $\mathrm{C}^{14}$ concentration, and 3) incorrect interpretation of the results.

A source of increasingly occurring false results is passage of impurities into the sample. To separate carbonate and humic impurities, organogenous material is treated with acids and alkaline pyrophosphate solution. To convince oneself of the correctness of the results, different carboniferous materials must be collected and dated from the same stratigraphic horizon, or the age of the different fractions (humic substances, cellulose, lignin) of the sample must be determined.

To avoid errors in the determination of the $\mathrm{C}^{14}$ concentration, one must pay due attention to the choice of standards, the check-up on the methods of synthesis of the counting preparation and a check on the counting techniques.

A few examples are given of the need to check $\mathrm{C}^{14}$ datings and the method of carrying. out a check-up. 